\title{
Increase in the Activities of Plasma Pseudocholinesterase Dependent on the Blood Glucose Level and Its Relation to the Hypersensitivity to Acetylcholine in Striated Muscles of KK-CA ${ }^{y}$ Mice with Diabetes
}

\author{
Tetsuo MATSUI, Ikuko KIMURA* and Masayasu KIMURA \\ Department of Chemical Pharmacology. Faculty of Pharmaceutical Sciences, \\ Toyama Medical and Pharmaceutical University. 2630 Sugitani. Toyama 930-01. Japan \\ Accepted May 14, 1990
}

\begin{abstract}
Acetylcholinesterase activity and pseudocholinesterase activity were examined in plasma and in striated muscles (whole heart and diaphragm muscles) of diabetic KK-CA mice. Both activities of acetylcholinesterase in heart muscle and pseudocholinesterase in plasma were significantly increased in diabetic KK-CA $\mathrm{A}^{y}$ mice compared to pre-diabetic KK-CA mice. Both acetylcholinesterase and pseudocholinesterase activities in skeletal muscle were not changed by the diabetic state. The increases in activity of plasma pseudocholinesterase was significantly correlated to the increase in blood glucose level in alloxan-, streptozotocin (STZ)-diabetic ddY mice and diabetic KK-CA $\mathrm{CA}^{y}$ mice. The increase was not correlated to the body weight in non-diabetic female-KK-CA mice. Furthermore, the activity of heart acetylcholinesterase was significantly correlated with the activity of plasma pseudocholinesterase $(r=0.79, P<0.01)$. The activities of acetylcholinesterases in heart muscles from STZ- and alloxan-diabetic ddY mice also tended to increase. The hypersensitivity of the pulse rate to a low dose $(1 \mathrm{mg} / \mathrm{kg})$ of acetylcholine was correlated to the activity of plasma pseudocholinesterase $(r=-0.51 . P<0.05)$. These results demonstrate that the activities of plasma pseudocholinesterase were increased by the diabetic state being associated with the increasing alteration of cardiac sensitivity to acetylcholine in the whole body.
\end{abstract}

Cardiac dysfunction and hypertension occur in experimental animals and humans with diabetes mellitus $(1,2)$. We have previously reported that both the increase in basal pulse rate and basal blood pressure in the diabetic state of streptozotocin-treated mice and diabetic KK-CA ${ }^{y}$ mice reflects the anticholinergic state (3). The resulting basal anticholinergic state is considered to be balanced both by parasympathetic and sympathetic control. The cardiac hypersensitivity to acetylcholine is induced by the diabetic state $(4,5)$. The sensitivity to acetylcholine is considered to be closely related to the activity of cholinesterase. Histochemical

"To whom correspondence should be addressed. stains for acetylcholinesterase (AChE) have shown that this enzyme is more rich in the sino-atrial node, Purkinje fibers, and atrioventricular node than in either atrial or ventricular myocardium, indicating a strong cholinergic innervation in these areas (6). The activities of pseudocholinesterase (pseudoChE) is reported to be higher than that of AChE in the atria of normal rats (7). In the present study, the activities of AChE and pseudoChE in heart muscle and in plasma was examined in diabetic mice, and we further investigated the relationship between the ChE activities and the hypersensitivity to acetylcholine of the pulse rate caused by the diabetic state. 


\section{Materials and Methods}

Animals: Genetically inbred diabetic KK$\mathrm{CA}^{y}$ male mice (AsaBBCC) (8) (31-36 weeks of age. $28.1-45.5 \mathrm{~g}$ body weight, 22.0-31.2 mM blood glucose (BG) level): prediabetic KK-CA: male (15-16 weeks of age, $27.0-40.8 \mathrm{~g}$ body weight, $6.1-10.3 \mathrm{mM}$ BG level); and female KK-CA ${ }^{y}$ mice (12-26 weeks of age, 23.0-60.0 g body weight, 4.4$23.2 \mathrm{mM} \mathrm{BG}$ level) of the same strain were used. $\mathrm{KK}-\mathrm{CA}^{y}$ mice were produced in our laboratory by mating male $\mathrm{KK}-\mathrm{CA}^{y}$ mice ( $A^{y} a B B C C$ ) with female KK-C mice (aa$\mathrm{BBCC})$

The ddY strain of mouse with streptozotocin (STZ) - and alloxan-induced diabetes was also used. This strain of mouse was purchased from Japan Shizuoka Laboratory Center. STZ (Sigma, $150 \mathrm{mg} / \mathrm{kg}$ ) or alloxan monohydrate (Nacalai. $85 \mathrm{mg} / \mathrm{kg}$ ) was dissolved in $0.9 \% \mathrm{NaCl}$ just before use and injected once into the tail veins of 4 -week-old ddY male mice (20.2-24.6 g body weight). Age-matched, non-diabetic ddY mice and ddY mice with chemically induced diabetes were used 4 to 5 weeks after the injection.

Mice were maintained under a constant temperature $\left(23 \pm 1{ }^{\circ} \mathrm{C}\right)$, fed the usual laboratory diet (CA-1. Japan Clea) and tap water freely, and with lights on from 8 a.m. to 6 p.m.

The blood samples were obtained at 10 a.m. from the orbital vein plexus. The $B G$ levels in the non-fasted state were measured by a glucose oxidase method using a Beckman glucose analyzer (Fullerton, CA, U.S.A., Type (I). The BG levels were confirmed just before isolation of the heart muscles.

Cholinesterase activity: Thirty microliters of blood was obtained from the periorbital venous plexus of mice, diluted four times with $0.9 \% \mathrm{NaCl}$ containing heparin $(20 \mathrm{U} / \mathrm{ml})$, and centrifuged at $3.000 \mathrm{rpm}$ for $10 \mathrm{~min}$ at $4^{\circ} \mathrm{C}$. The diluted sample of plasma was stored at $4^{\circ} \mathrm{C}$ and assayed for cholinesterase activity within $24 \mathrm{hr}$.

After a cannula was introduced into the left femoral vein under urethane $(1.5 \mathrm{~g} / \mathrm{kg}$, i.p.) anesthesia, the mouse was exsanguinated by perfusion with $15-20 \mathrm{ml}$ of $0.9 \% \mathrm{NaCl}$. The whole heart and diaphragm muscles were then removed, cleaned of connective tissue, and washed in cold antiprotease buffer containing $50 \mathrm{mM}$ of sodium phosphate $(\mathrm{pH}$ 7.4). $4 \% \mathrm{w} / \mathrm{v}$ sucrose, $1 \% \mathrm{v} / \mathrm{v}$ Triton $\mathrm{X}-100$. $1 \mathrm{mg} / \mathrm{ml}$ bacitracin, $2 \mathrm{mM}$ benzamidine hydrochloride, $20 \mu \mathrm{g} / \mathrm{ml}$ pepstatin, and $5 \mathrm{mM}$ $\mathrm{N}$-ethylmaleimide. The muscles were blotted, weighed, minced, and homogenized 5 times for 30 sec a homogenizer (Ikemoto Instruments). Homogenates were centrifuged at $16,000 \times \mathrm{g}$ for $10 \mathrm{~min}$ at $4^{\circ} \mathrm{C}(7)$. The muscle extracts were stored at $4{ }^{\circ} \mathrm{C}$ and then assayed for cholinesterase activity within $24 \mathrm{hr}$.

AChE activity was assayed by a modification of the method of Ellman et al. (9) in a reaction medium containing $0.3 \mathrm{mM} 5.5^{\circ}$ dithio-bis(2-nitrobenzoic acid) (DTNB)-0.1 $M$ of phosphate buffer ( $\mathrm{pH} 8.0)$. An 0.2-ml sample of heart muscle extract or a $10-u l$ sample of plasma was added to the reaction medium. After incubation at $37^{\circ} \mathrm{C}$ for $30 \mathrm{~min}$ to inactivate pseudoChE completely in the presence of $0.1 \mathrm{mM}$ ethopropazine hydrochloride, the reaction was initiated by adding acetylthiocholine iodide (at the final concentration of $0.5 \mathrm{mM}$ ) as a substrate (total volume, $3.12 \mathrm{ml}$ ). The reaction mixture was incubated at $37^{\circ} \mathrm{C}$ for $30 \mathrm{~min}$, and then the reaction was stopped by adding $1 \mathrm{mM}$ of neostigmine methylsulfate per liter. The pseudoChE activity was measured by the same method as above, by adding $0.5 \mathrm{mM}$ butyrylthiocholine iodide instead of acetylthiocholine and $0.01 \mathrm{mM}$ BW284C51 (1.5bis(4 - allyl - dimethyl - ammoniumphenyl)pentane-3-one dibromide, an AChE inhibitor) instead of ethopropazine. A blank assay was performed by using the same volume of phosphate buffer instead of sample. Both ChE activities were measured by following the increase in absorbance at $415 \mathrm{~nm}$ of the yellow compound (5-thio-2-nitrobenzoic acid) in a spectrophotometer (101. Hitachi). Activity is presented in units of micromoles of substrate hydrolyzed per min per gram wet weight of heart muscle or per $\mathrm{ml}$ of plasma. The following drugs or reagents were used: acetylthiocholine iodide. S-butyrylthiocholine iodide, 5.5'-dithio-bis(2-nitrobenzoic acid) (DTNB), bacitracin, benzamidine hydrochloride, N-ethylmaleimide (Wako), neostigmine methylsulfate, ethopropazine hydro- 
chloride, BW284C51, heparin, pepstatin A (Sigma), urethane and Triton X-100 (Nacalai).

Measurement of pulse rate: The pulse rate were determined by a tail-artery-cuffing technique using a photoelectric sensor plethysmograph in unheated and conscious mice (PS-200, Riken Kaihatsu) (3). The values of pulse rate obtained by this technique have been confirmed by using electrocardiography and a direct cannulation method performed simultaneously under urethane anesthesia.

Statistical analysis: Differences between diabetic and non-diabetic or prediabetic mice were analyzed for significance by using Student's range test. $A C h E$, pseudoChE, and BG level, or pseudoChE, BG level, and body weight were analyzed for multiple correlation (10)

\section{Results}

Diabetic state-induced change in plasma pseudocholinesterase and heart or skeletal muscle acetylcholinesterase from prediabetic and diabetic KK-CA mice: Both the activities of AChE and pseudoChE in the diaphragm muscle were not changed by the diabetic state in KK-CA ${ }^{y}$ mice (Fig. 1a) and in diaphragm muscles of STZ-diabetic and alloxan-diabetic mice (data not shown). The activity of AChE in skeletal muscle was 2.5 -fold greater than that in heart muscle, although the activity of pseudoChE in skeletal muscle was the same as that in heart muscle (Fig. 1b).

In the diabetic $K K-C A^{v}$ male mice, the AChE activity in the heart and the pseudoChE activity in the plasma were significantly increased when compared to the prediabetic one (Fig. 1c).

Correlation among heart acetylcholinesterase, plasma pseudocholinesterase, blood glucose level and body weight: Blood glucose levels were $7.6 \pm 0.5(n=8)$ and $25.8 \pm 0.9 \mathrm{mM}$ $(n=10)$ in the prediabetic and diabetic KK-
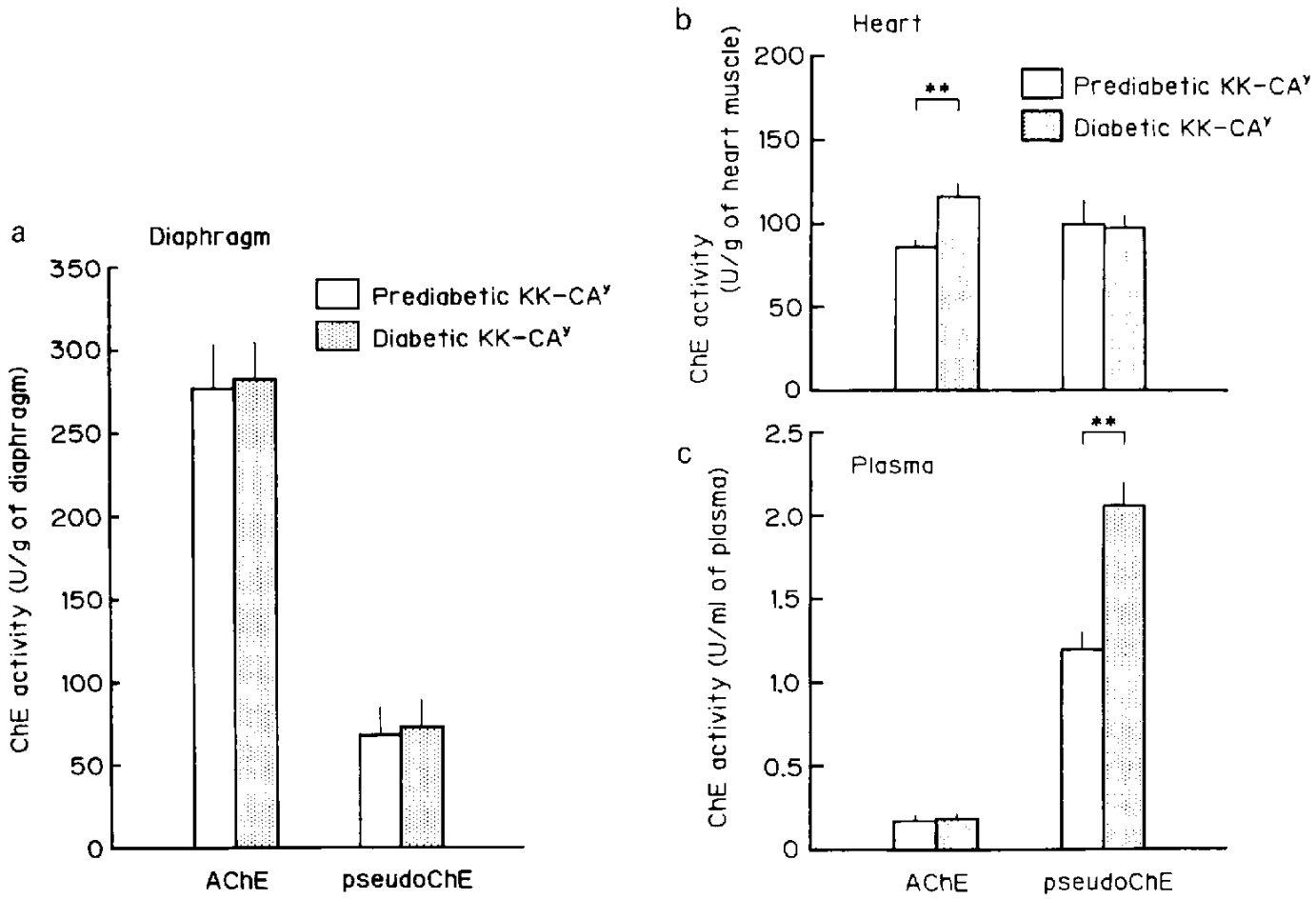

Fig. 1. Acetylcholinesterase (AChE) activity and pseudocholinesterase (pseudoChE) activity in skeletal muscle (a), heart muscle (b), and in plasma (c) from prediabetic and diabetic KK-CAy mice. Each column represents the mean $\pm S$.E. M. of 6 to 10 animals. ${ }^{* *} \mathrm{P}<0.01$, significantiy different from prediabetic KK-CAY mice by Student's range test. 
$\mathrm{CA}^{r}$ male mice and were $7.4 \pm 0.3(n=10)$, $29.1 \pm 1.1(n=10)$, and $27.2 \pm 1.0 \mathrm{mM}(n=10)$ in the non-diabetic. STZ-diabetic and alloxan-diabetic ddY mice, respectively. In a correlation analysis of two parameters in KK$\mathrm{CA}^{y}$-, STZ- and alloxan-diabetic male mice. the activity of the heart AChE was correlated positively with the activity of plasma pseudoChE. Activities of plasma pseudoChE were correlated positively with the blood glucose levels (Fig. 2, Table 1). In the obese KK-CA: female mice $(50.5 \pm 1.1 \mathrm{~g}$ body weight, $n=61)$ compared to the diabetic KK-CA ${ }^{y}$ male mice $(39.8 \pm 0.4 \mathrm{~g}, n=306)$, the activity of plasma pseudoChE was not correlated with the body weight. No correlation between AChE activity and age was observed in KK-CA ${ }^{y}$ mice (data not shown).

Diabetic state-induced changes in heart acetylcholinesterase and plasma pseudocholinesterase activity in ddY mouse with streptozotocin or alloxan: The activities of $\mathrm{AChE}$ and pseudoChE in the heart muscle or in the plasma from STZ- or alloxan-diabetic ddY mice were compared to those from the non-diabetic mice (Fig. 3). The AChE activity in the heart muscle tended to be higher in both diabetic mice than in the non-diabetic ones. The pseudoChE activity in the plasma was significantly $(P<0.01)$ increased in the alloxan-diabetic mice compared to the nondiabetic ones, while it tended to be higher in the STZ-diabetic mice. On the other hand, the pseudoChE activity in the heart muscle and

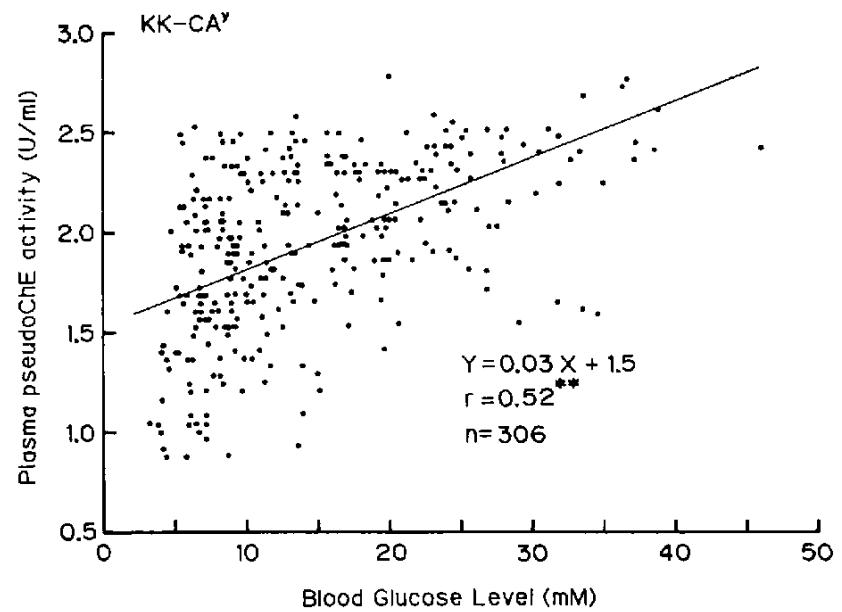

Fig. 2. Correlation between plasma pseudocholinesterase activity and blood glucose level in KK-CAY male mice. Each point is the value obtained from a single animal $(n=306)$. The plasma pseudoChE activity was significantly correlated with the blood glucose level $(P<0.01)$.

Table 1. Correlation coefficients among heart acetylcholinesterase (AChE) activity, plasma pseudocholinesterase (pseudoChE) activity, blood glucose (BG) level and body weight (BW) in KK-CAY-. streptozotocin (STZ) - and alloxan-diabetic ddY mice

\begin{tabular}{|c|c|c|c|c|c|c|}
\hline & \multicolumn{3}{|c|}{$\mathrm{KK}-\mathrm{CA}^{\mathrm{y}}$} & \multicolumn{3}{|c|}{$d d Y$} \\
\hline & \multicolumn{2}{|c|}{ Male } & \multirow[t]{2}{*}{ Female } & \multicolumn{3}{|c|}{ Male } \\
\hline & Pre & Diabetic & & Normal & STZ & Alloxan \\
\hline Heart AChE_Plasma pseudoChE & 0.26 & $0.79^{* *}$ & & 0.28 & $0.71 * *$ & $0.61^{* *}$ \\
\hline Plasma pseudoChE-BG & 0.30 & $0.52 * * a$ & & 0.34 & $0.63^{* *}$ & $0.59^{* *}$ \\
\hline Plasma pseudoChE-BW & & $0.35 * * a$ & 0.23 & & & \\
\hline$n$ & 8 & 18 & 61 & 10 & 20 & 20 \\
\hline
\end{tabular}

in $n=306 . \quad{ }^{*} P<0.01$ (two-tailed Student's $t$-test) 

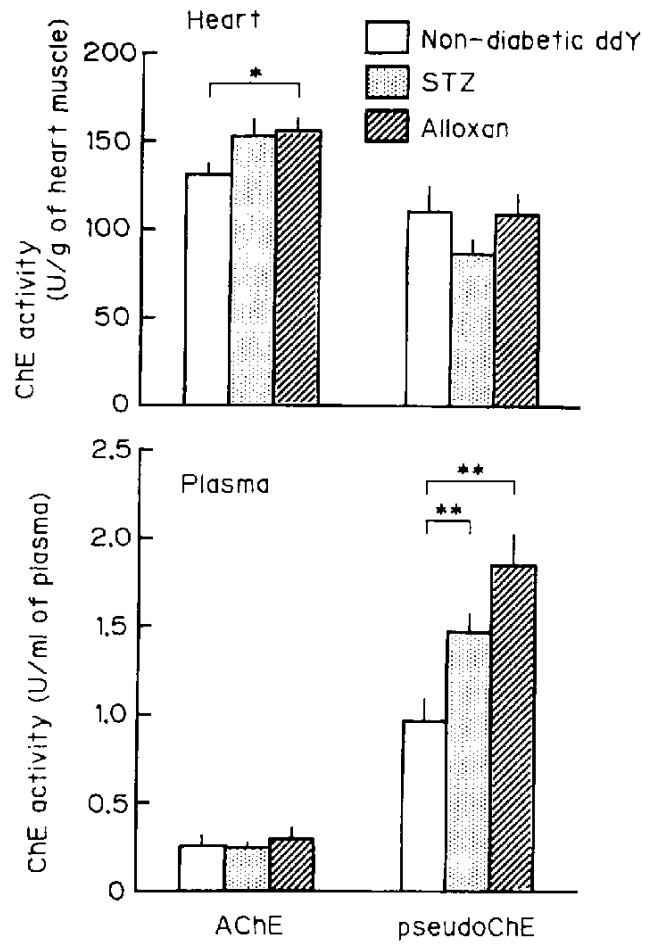

Fig. 3. Acetylcholinesterase activity and pseudocholinesterase activity in heart muscle (upper) and plasma (lower) from age-matched non-diabetic ddY and alloxan- and streptozotocin (STZ)-diabetic ddY mice. Each column represents the mean \pm S. E.M. of 10 animals. ${ }^{*} P<0.05$ and ${ }^{*} P<0.01$. significantly different from age-matched non-diabetic ddY mice by Student's range test. the AChE activity in the plasma were not changed by the diabetic state.

Multiple correlation among the acetylcholine-induce pulse rate response, the dose of acetylcholine and the activity of plasma pseudocholinesterase in the prediabetic and the diabetic $\mathrm{KK}^{-\mathrm{CA}^{y}}$ mice: The multiple relationships among the $\mathrm{ACh}$-induced pulse rate response, the dose of acetylcholine, and the activity of plasma pseudoChE were threedimensionally plotted for the KK-CA ${ }^{y}$ male mice (Fig. 4). As the dose of acetylcholine was increased from 1 to $30 \mathrm{mg} / \mathrm{kg}$, the pulse rate responses were changed to the negative direction from the positive one. Although the multiple correlation was not observed among the above three parameters, the ACh-induced pulse rate responses were negatively correlated with the activity of plasma pseudoChE only at $1 \mathrm{mg} / \mathrm{kg}$ acetylcholine $(r=-0.51, \mathrm{n}=$ 16. $P<0.05)$.

\section{Discussion}

The present study demonstrated that both activities of $A C h E$ in the heart muscle and pseudoChE in the plasma were increased in parallel by the diabetic state of KK-CA mice. The pseudoChE in the heart muscle was not changed by the diabetic state. The AChE activity was higher in the heart muscle from the diabetic KK-CA ${ }^{y}$ mice than from the pre-

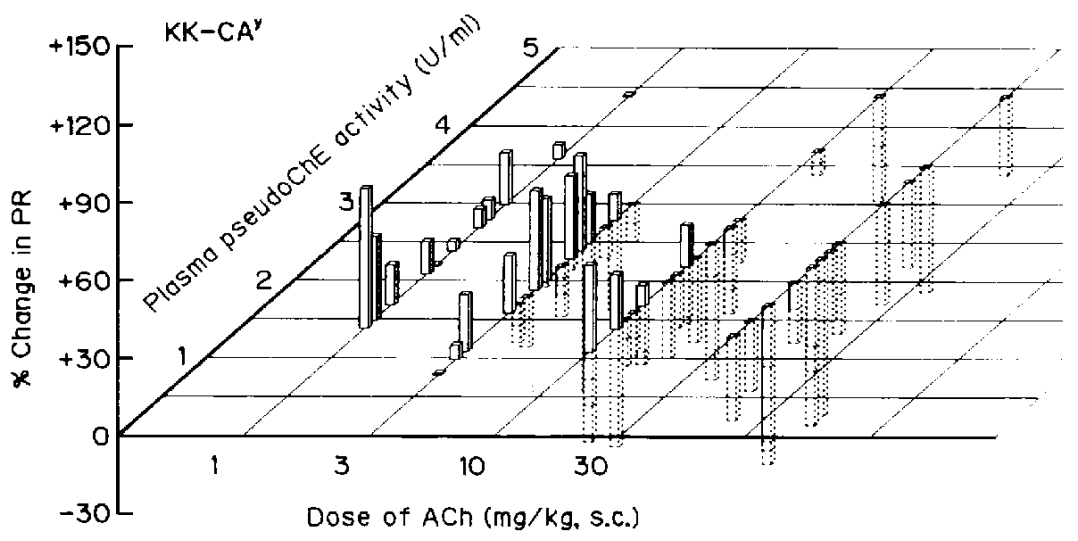

Fig. 4. Three-dimensional plots of the dose-response effect of acetylcholine (ACh) on pulse rate (PR) and the plasma pseudocholinesterase activity in prediabetic and diabetic KK-CAy male mice. The solid column represents a positive chronotropic response. while the dotted column represents a negative chronotropic one. Each column represents the value obtained from a single animal $(n=99)$. The AChinduced PR response was significantly correlated with the plasma pseudoChE activity at the dose of $1 \mathrm{mg} /$ $\mathrm{kg} \operatorname{ACh}(r=-0.51, P<0.05, n=16)$. 
diabetic mice, and it tended to increase in the heart muscle from STZ- and alloxan-diabetic ddY mice. The activities of heart AChE and plasma pseudoChE were significantly correlated, respectively, with the $B G$ level in the $\mathrm{KK}-\mathrm{CA}^{y}$ male mice, indicating the serious involvement of the glucose metabolism in $\mathrm{ChE}$ activities. An increase in the ChE activity may decrease the effective concentration of ACh acting on the myocardial receptors. Some investigators reported that the AChE activity in the heart decreased in STZdiabetic rats, that acetylcholine contents in the nerve ending increased, and that postsynaptic muscarinic receptors were downregulated $(4,11)$. This apparent discrepancy may be due to a difference in the region of the heart used for the assay of AChE activity. They used the right atrium, whereas we used the whole heart, because the aim in the present study was restricted to the relation between the activity of cholinesterase in the whole heart and the pulse rate to $\mathrm{ACh}$ in the whole body.

The AChE activity increases with age (12). However, no correlation between $A C h E$ activity and age was observed in KK-CA ${ }^{*}$ male mice (data not shown). The lower extent of increase of $\mathrm{AChE}$ activity in the heart muscle of STZ-or alloxan-diabetic mice may be due to the short term duration (4-5 weeks) compared to the long-term duration (15-20 weeks) of diabetes (KK-CA mice). The increase in heart $A C h E$ activity seemed not to be related with a hypertrophy of the heart muscle, because the wet weights of heart muscles in diabetic KK-CA $A^{y}$ mice were not different from those in the prediabetic ones (13). The plasma pseudoChE activity was higher in the diabetic KK-CA mice than in the prediabetic ones. An abnormality in lipid metabolism may cause the induction of pseudoChE in the liver of the diabetic mice as shown in the experimental obese mice (14). Since there were no correlations between plasma pseudoChE activity and body weight in the KK-CA female mice, the increase in plasma pseudoChE can not be attributed to obesity.

The blood insulin levels in diabetic KK-CA male mice are 4.7-fold higher than those in KK-C male mice, but only 1.2 -fold lower than that in KK-CA female mice (8). The high level of cholinesterase activity in the diabetic state, therefore, seems not to be related to the insulin level.

The plasma AChE activity was 5 - to 10 fold less than the plasma pseudoChE activity, and it was not changed by the diabetic state. Usually, the regulation of $\mathrm{AChE}$ is tissuespecific, whereas pseudoChE depends on a homeostatic type of regulation through the whole body (15). The present study indicated that AChE in the heart muscle and pseudoChE in the plasma were regulated in parallel in the diabetic KK-CA mice. Whether the positive correlation between both ChE activities has an important meaning is not clear. Based on the parallel regulation of heart AChE activity and plasma pseudoChE activity, the relationships between plasma pseudoChE activity and alteration of the sensitivity of the pulse rate to acetylcholine were analyzed in diabetic KK-CA ${ }^{y}$ mice. A negative correlation was observed only at a low dose of acetylcholine (1 $\mathrm{mg} / \mathrm{kg}$ ), which may produce the critical concentration of acetylcholine in the plasma enabling its hydrolysis, by plasma ChE. The heart rate and the contractile response in skeletal muscles are generally hypersensitive to acetylcholine in the diabetic state (16). These hypersensitivities may be caused in part by the increase in the activity of plasma ChE. The effects on heart rate are balanced both by parasympathetic and sympathetic control in the non-diabetic state, but are unbalanced in the diabetic state. Generally, such an unbalanced state may cause a deflection syndrome (over-parasympathetic) (Reilly phenomena; 17,18 ) due to a low level of acetylcholine in the whole body.

In conclusion. AChE activity in the heart muscle and pseudoChE activity in the plasma were increased inparallel in diabetic $\mathrm{KK}-\mathrm{CA}^{\mathrm{y}}$ mice. The same tendency was observed in the STZ- and alloxan-diabetic ddY mice. The increase in the ChE activities in the diabetic state may contribute to the increasing alterations of cardiac sensitivity to acetylcholine in the whole body.

\section{References}

1 Regan, T.J., Ettinger, P.O., Khan, M.I., Jesrani, M.U., Lyons, M.M., Oldewurtel, H.A. and Weber, 
M.: Altered myocardial function and metabolism In chronic diabetes mellitus without ischemia in dogs. Circ. Res. 35, 222-237 (1974)

2 Regan. T.J., Lyons, M.M., Ahmed, S.S., Levinson, G.E., Oldewurtel, H.A., Ahmad, M.R. and Haider, B.: Evidence for cardiomyopathy in familial diabetes mellitus. J. Clin. Invest.60, 885-899 (1977)

3 Kimura, I., Matsui, T. and Kimura, M.: Increase in basal pulse rate and blood pressure by the diabetic state in KK-CA ${ }^{y}$ mice, alloxan-mice and streptozotocin-mice. Japan. J. Pharmacol. 46, 93-96 (1988)

4 Carrier, G.O. and Aronstam, R.S.: Altered muscarinic receptor properties and function in the heart in diabetes. J. Pharmacol. Exp. Ther. 242, $531-535$ (1987)

5 Matsui, T., Kimura, I. and Kimura, M.: Multiple correlation among the putse rate response to acetylcholine, blood glucose and the activity of plasma cholinesterase in diabetic mice. Folia Pharmacol. Japon. 92, 71P (1988) (in Japanese)

6 James, T.N. and Spence, C.A.: Distribution of cholinesterase within the sinus node and AV node of the human heart. Anat. Rec. 155, 151162 (1966)

7 Edwards, J.A. and Brimijoin, S.: Effects of hypophysectomy on acetylcholinesterase and butyrylcholinesterase in the rat. Biochem. Pharmacol. 32, 1183-1189 (1983)

8 Kimura, M., Suzuki, J. and Amemiya, K.: A geneticaliy diabetic model "KK-CAy mice" for a pharmacological assay. Endocrinol Japon. 26, 185195 (1979)

9 Ellman, G.L., Courtney, K.D., Anders, V., Jr. and Featherstone, R.M.: A new and rapid colorimetric determination of acetylcholinesterase activity. Biochem. Pharmacol. 7. 88-95 (1961)

10 Kimura, M., Kimura, I., Nakamura, T. and Nojima, $H$.: Diabetic state-induced modification of resting membrane potential and conductance in diaphragm muscle of alloxan and diabetic KK-CAy mice. Diabetologia 31, 103-107 (1988)

11 Akiyama, N., Okumura, K., Watanabe, Y., Hashimoto, H., Ito, T., Ogawa, K. and Satake, T.: Altered acetylcholine and norepinephrine concentrations in diabetic rat hearts: Role of parasympathetic nervous system in diabetic cardiomyopathy. Diabetes 38, 231-236 (1989)

12 Smith, D.O. and Emmerling, M.: Biochemical and physiological consequences of an agerelated increase in acetylcholinesterase activity at the rat neuromuscular junction. J. Neurosci. 8, 3011-3017 (1988)

13 Nakagawa, M., Kobayashi, S., Kimura, I. and Kimura, M.: Diabetic state-induced modification of contents of $\mathrm{Ca}, \mathrm{Mg}$. Fe and $\mathrm{Zn}$ in skeletal, cardiac and smooth muscles. Endocrinol. Japon. 36, 795-807 (1989)

14 Kutty, K.M., Huang, S.N. and Kean, K.T.: Pseudocholinesterase in obesity: Hypercaloric diet induced changes in experimental obese mice. Experientia 37, 1141-1142 (1981)

15 Chatonnet, $A$, and Lockridge, O.: Comparison of butyrylcholinesterase and acetylcholinesterase. Biochem. J. 260, 625-634 (1989)

16 Kimura, M., Kimura, I., Nojima, $H$. and Muroi, M.: Diabetes mellitus-induced hypersensitivity of mouse skeletal muscles to acetylcholine and succinylcholine. Japan. J. Pharmacol. 40, 251256 (1986)

17 Reilly, J., Rivalier, E., Compagnon, A. and Laplane, R.: Hémorrhagie lésion vasculaires et Iymphatiques du tube digéstif déterminées par l'injection périsplanchnique de substances diverse. C.R. Soc. Biol. 116, 24 (1934)

18 Reilly, J.: L'irritation neuro-végétative et son rôle en pathologie. C.R. Soc. Biol. 48, 1374-1384 (1954) 